Araştırma Makalesi / Research Paper

\title{
Entomopatojen Fungus, Beauveria bassiana (Balsamo)'nın İki Farklı İzolatının Myzus persicae Üzerine Ölümcül Etkileri
}

\author{
Gizem BERBER (iD) , Ali Kemal BíRgÜCÜ (iD) 1* \\ ${ }^{1}$ Isparta Uygulamalı Bilimler Üniversitesi, Ziraat Fakültesi, Isparta \\ Geliş Tarihi (Received): 02.07.2020, Kabul Tarihi (Accepted): 04.10.2020 \\ $\square$ Sorumlu Yazar (Corresponding author*): alibirgucu@isparta.edu.tr \\ (C) +902462146281 氛 +902462146399
}

\section{ÖZ}

Bu çalışmada Myzus persicae Sulzer (Hemiptera: Aphididae) üzerine entomopatojen fungus Beauveria bassiana'nın LD.2016 ve M6-4 izolatlarının etkinliğinin belirlenmesi amaçlanmıştır. Bu kapsamda B. bassiana'nın her iki izolatının $10^{6}, 10^{7}$ ve $10^{8}$ konidi.ml- $^{-1}$ dozları kullanılmıştır. Her bir doz ve kontrol grubu için denemeler 50 tekerrürlü olacak şekilde kurulmuştur. Her bir petri kabındaki yavrular 2. veya 3. nimf dönemine geldiğinde entomopatojen fungusun spor süspansiyonuna beş saniye süre ile daldırılmıştır. Yüzde ölüm oranlarını hesaplamak amacıyla uygulamadan

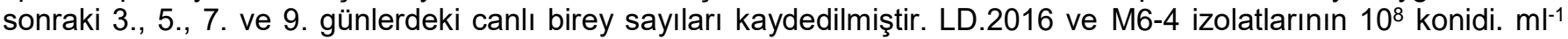
uygulamasındaki $\mathrm{LT}_{50}$ değerleri sırasıyla 6.19 ve 5.5 gün olarak bulunmuştur. Elde edilen verilere göre, doz arttıkça uygulamadan sonraki 3., 5., 7. ve 9. günlerdeki ölüm oranlarının da arttığı belirlenmiştir. Uygulamadan sonraki 9.

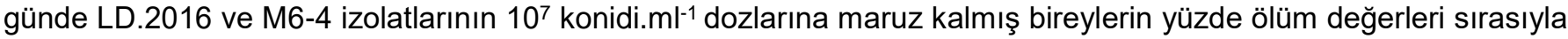
$\% 58$ ve \%70 olarak bulunmuştur. LD.2016 ve M6-4 izolatlarının $10^{8}$ konidi.ml $^{-1}$ dozlarına maruz kalmış bireylerin yüzde ölüm değerleri ise sırasıyla $\% 98$ ve $\% 92$ olarak bulunmuştur. En iyi etki her iki izolatta da $10^{8} \mathrm{konidi}^{-1} \mathrm{ml}^{-1}$ doz uygulamalarında görülmüştür. Sonuç olarak insanlara ve çevreye daha az zararı olan entomopatojen fungus $B$. bassiana izolatlarının $M$. persicae kontrolünde biyolojik mücadele etmeni olarak kullanabileceği düşünülmektedir.

Anahtar Kelimeler: Biber, biyolojik mücadele, entegre zararlı yönetimi, mortalite, yaprakbiti

\section{Lethal Effects of Two Different Isolates of Entomopathogen Fungus Beauveria bassiana (Balsamo) on Myzus persicae}

\begin{abstract}
The study aimed to determine the effectivity of LD.2016 and M6-4 isolates of entomopathogen Beauveria bassiana

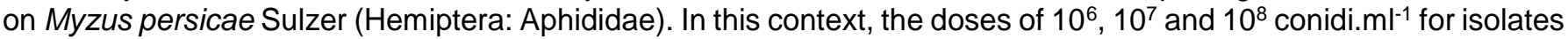
were used. Experiments for each dose and control group were set up to be 50 repeats. The aphids reached the $2^{\text {nd }}$ or $3^{\text {rd }}$ nymph period were dipped in the spore suspension of the entomopathogen for five seconds. To calculate the mortality on the $3^{\text {rd }}, 5^{\text {th }}, 7^{\text {th }}$ and $9^{\text {th }}$ days after the application the living individuals were recorded. $L T_{50}$ values of LD.2016 and M6-4 isolates were 6.19 and 5.5 days, respectively at $10^{8}$ conidi.ml-1 dose. Based on the obtained data, it is observed that mortality was increased while the doses were raised at the $3^{\text {rd }}, 5^{\text {th }}, 7^{\text {th }}$ and $9^{\text {th }}$ days after the application. On the $9^{\text {th }}$ day after application, the percentage mortality values of individuals exposed to $10^{7}$ conidi.ml-1 doses of LD.2016 and M6-4 isolates were found to be $58 \%$ and $70 \%$, respectively. Percentage mortality of individuals exposed to $10^{8}$ conidi.ml $^{-1}$ doses of LD.2016 and M6-4 isolates was $98 \%$ and $92 \%$, respectively. The highest effects of

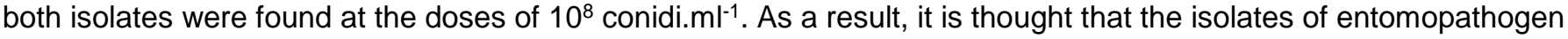
$B$. bassiana, less harmful to humans and the environment, can be used as a biological control agent in the controlling of the pest.
\end{abstract}


Keywords: Pepper, biological control, integrated pest management, mortality, aphid

\section{Giriş}

Polifag bir zararlı olan yeşil şeftali yaprakbiti, Myzus persicae (Sulzer, 1776) (Hemiptera: Aphididae) ülkemizde farklı bitkiler üzerinde zararlı olup uygun koşullarda yıl boyunca üremeye ve zarar yapmaya devam edebilmektedir (Velioğlu ve Toros, 2002). M. persicae bireyleri bitkilerin özsuyunu emerek zararlı olup emgi sırasında da bitkiye toksik madde salgılarlar. Ballımsı madde salgılayarak da fumajine neden olurlar. Diğer bir zararı ise virüs vektörü olmasıdır (Özçelik ve ark., 2013). Ayrıca M. persicae, çok fazla konukçuya sahip olması, yılda birçok döl vermesi ve kısa sürede üremesi sebebiyle mücadelesi zor bir zararlıdır (Özçelik ve ark., 2013).

Birçok zararlı da olduğu gibi $M$. persicae ile mücadelede de kimyasal pestisitler kullanılmaktadır. Kimyasal pestisitlerin ürünlerde kalıntı bırakması, insan ve çevreye olan riskleri ve zararlılarda direnç oluşturması nedeniyle alternatif mücadele yöntemi olan biyolojik mücadeleye yönelim olmuştur (Erdoğan, 2015). Kimyasal mücadelenin insanlara ve çevreye olan riskleri düşünüldüğünde biyolojik mücadele en güvenilir metotlardan biridir. $M$. persicae mücadelesi için şimdiye kadar pek çok biyolojik savaş etmeni üzerinde çalışılmıştır (Özçelik ve ark., 2013).

Zararlılar ile mücadelede, hastalığa sebep olan oganizmaların uygulanmasına mikrobiyal savaşım denir. Mikroorganizmaların en uygun kullanımı, yapay besi yerlerinde kültürlerinin oluşturulması sonra da uygun bir ortamda ve zamanda doğaya dengeli bir şekilde verilmesidir (Çelebi, 2012). Entomopatojen funguslar doğrudan böcek kutikulasından giriş yaptığı için zararlı tarafından yenilerek vücut içerisine alınmalarına gerek yoktur. Bundan dolayı, besin kaynağı bitki öz suyu olan böceklerin mücadelesinde entomopatojen funguslar önemli bir yere sahiptir. Yaklaşık olarak 1900'lü yıllardan beri entomopatojen funguslardan biyolojik savaş etmeni olarak faydalanılmaktadır (Sevim ve ark., 2015).

Bugüne kadar, en az 90 cinse ait 700 entomopatojen fungus türü belirlenmiştir. Dünya'nın pek çok yerinde zararlılara karşı Beauveria bassiana (Bals.) Vuill., Metarhizium anisopliae (Metsch.) Sorok., Isaria fumosorosea (=Paecilomyces fumosoroseus) Wize ve Lecanicillium lecanii (Zimm.) Zare \& Gams'ye benzer fungus türleri ticari amaç doğrultusunda geliştirilmektedir (Rath, 2000). Entomopatojen fungusların memelilere karşı zehirli olmamaları, zararlılarda direnç oluşturmamaları, doğada uzun süreli mücadele etmeleri, böceğin bütün gelişme dönemlerinde etkili olabilmeleri, çoğu insektisitler ile beraber uygulanabilmeleri, ucuz ve uygulamalarının kolay olması gibi pek çok kayda değer yararları vardır (Sevim ve ark., 2015). Bitki ile beslenen böceklerin mücadelesinde ticari şekilde üretilmiş $B$. bassiana ve $M$. anisophile izolatlarının, arılara karşı risklerinin olmadığı saptanmış ve biyolojik savaş etmeni olarak uygulanabilir olduğu belirtilmiştir (Uzuner ve ark., 2017).

Entomopatojen funguslar üzerine yapılan araştırmalarda, ortam nem düzeyi ile doğru orantılı olarak etkilerinin de artış gösterdiği belirtilmiştir (Demirci ve ark., 2011). Geliştirilen biyopestisitlerden, Lagenidium giganteum Couch, sivrisinek larvalarının; $M$. anisopliae, hamam böceği ve sineklerin; Aschersonia aleyrodis Webber, beyazsinek türlerinin; $B$. bassiana'nın ise elma iç kurdu, patates böceği, diğer bazı Coleoptera ve Lepidoptera takımına bağıı türlere karşı uygulanabildikleri belirtilmektedir (İnanlı ve ark., 2012).

Dünya genelinde tarım alanlarındaki topraklarda bol miktarda görülen $B$. bassiana çok fazla konukçuya sahiptir (Güven ve ark., 2014). Günümüze kadar, B. bassiana'nın 707 tane değişik konukçusu olduğu belirtilmiştir. Bunlar içinde 521 cins, 149 familya ve 15 takım bulunmaktadır (Zimmermann, 2007). B. bassiana, Lepidoptera, Coleoptera, Hymenoptera, Diptera, Hemiptera, Orthoptera, Siphonaptera, Isoptera, Thysanoptera, Mantodea, Neuroptera, Dermaptera, Blattariae ve Embioptera takımlarında hastalık oluşturmaktadır (Zimmermann, 2007). Çin'e özgü olarak geliştirilen B. bassiana'nın, Mısır kurdu Ostrinia nubialis Hbn. (Lepidoptera: Crambidae)'in ve Çam tırtılı (Dendrolimus spp.)'nın mücadelesinde kullanıldığı bildirilmiştir. Türkiye'de de Patates böceği, Leptinotarsa decemlineata Say. (Coleoptera: Chrysomelidae) mücadelesinde entomopatojen fungus $B$. bassiana'nın etkin olarak kullanabileceğini bildirmişlerdir (Azizoğlu ve ark., 2012). Yine aynı çalışmada, ekolojik tarımda çok yıllık bitkilerde meyve sinekleri ve mayıs böceklerinin, sebze ve örtü altı bitkilerinde yaprakbitlerinin ve beyazsineklerin mücadelesinde entomopatojen fungusların çoğunun üretici tarafından genellikle uygulandıklarını belirtmişlerdir.

Bu çalışmada, entomopatojen fungus $B$. bassiana'nın LD.2016 ve M6-4 izolatlarının $10^{6}, 10^{7}$ ve $10^{8}$ konidi.ml- $^{-1}$ dozlarının M. persicae'ye etkilerinin belirlenmesi amacıyla, yüzde ölüm değerleri hesaplanarak popülasyonun yarısının öldüğü süre ( $\left(T_{50}\right)$ belirlenmiştir. Böylece entegre zararlı yönetimi kapsamında kullanım olanağının olup olmadığı belirlenmeye çalışılmıştır.

\section{MATERYAL VE YÖNTEM}

$\mathrm{Bu}$ çalışmanın ana materyalini biber bitkisi [Capsicum annuum (Personatae: Solanaceae) (Var. Lotus)], Myzus persicae Sulzer (Hemiptera: Aphididae) bireyleri, Isparta 
il merkezinde tarımsal faaliyetlerin yürütüldüğü toprak örneklerinden "Galleria tuzak metodu" (Zimmermann, 1986 ) ile izole edilen ön patojenite testi sonucu patojenitesi yüksek bulunan Beauveria bassiana (Bals.) Vuill izolatı (BMAUM M6-4) ve Süleyman Demirel Üniversitesi kampüsünden toplanan ergin Leptinotarsa decemlineata (Say) (Coleoptera: Chrysomelidae)'dan izole edilen diğer B. bassiana izolatı (BMAUM LD.2016) oluşturmaktadır (Baydar ve ark., 2016).

\section{Biber bitkilerinin yetiştirilmesi}

Bitki üretimi için Solanaceae familyasından Üç burun F1 biber çeşidi (Capsicum annuum L.) kullanılmıştır. Biber fideleri, Isparta Uygulamalı Bilimler Üniversitesi, Ziraat Fakültesi, Bitki Koruma Bölümü iklim odalarında yetiştirilmiştir. Sterilize edilmiş olan toprak, saksıların yarısına kadar doldurulup üzerine biber fideleri koyularak şaşırtma işlemi yapılmıştır. Şaşırtılmış olan biber bitkileri küvetlere yerleştirilmiştir. Temiz iklim odalarına taşınarak can suyu verilmiştir ve daha sonra 2-3 gün aralıklarla düzenli sulama yapılmıştır. Fidelerin yetiştirilmesi sırasında herhangi bir gübre ve ilaç uygulaması yapılmamıştır. Hastalık ve zararlı görülen bitkiler ortamdan uzaklaştırılmıştır.

\section{Myzus persicae bireylerinin üretimi}

Denemede kullanılan yaprakbitleri, iklim odalarında biber bitkisi üzerinde üretilmiştir. $M$. persicae üretimi ve devamlılığı için iklim kabinlerinde $25_{ \pm} 1^{\circ} \mathrm{C}$ ve $\% 60_{ \pm} 5$ orantılı nem koşulları sağlanmıştır. Stok kültürden aldığımız M. persicae ile bulaşık yapraklar, şaşırtmış olduğumuz biber fidelerinin üzerine aktarılarak bulaşma sağlanmıştır. Böcek kültürünün sürekliliğini sağlamak için gerektiğinde yıpranmış bitkiler temizleri ile değiştirilmiştir. Deneme süresince bitkilere herhangi bir ilaç ve gübre uygulaması yapılmamıştır. Hastalık ve zararlı görülen bitkiler ortamdan uzaklaştırıımıştır.

\section{Entomopatojen fungusların hazırlanması}

Denemede kullanılan entomopatojen fungus izolatları, Sabouraud Dekstroz Agar (SDA) besi yerinde kültüre alınmıştır. SDA (65 g/l, Biolife $\left.{ }^{\circledR}\right)$ saf su ile hazırlanıp 500 ml'lik cam erlenmayer şişelerine konularak otoklavda $121^{\circ} \mathrm{C}$ 'de 20 dakikada steril edilmiştir. Oda sıcaklığına soğutulan steril edilmiş SDA yeni fungus kültürü oluşturulmak üzere petri kaplarına $(9 \mathrm{~cm})$ dökülmüştür.
Saf kültürlerden entomopatojen fungus sporları alınarak $12-15 \mathrm{ml}$ besi yeri içeren petri kaplarına yayılarak aseptik koşullarda taze kültür oluşturulmuştur. Petri kapları $20-25^{\circ} \mathrm{C}$ 'de $\% 75$ nem ortamında karanlıkta inkübe edilmiştir.

SDA içeren petri kaplarında $25 \pm 1^{\circ} \mathrm{C}$ ve $\% 60 \pm 5$ nemli ortamda karanlıkta inkübe edilen 14 günlük fungus kültürlerinden hafifçe kazıyarak toplanan sporlar \%0.05 Tween 80 içeren $50 \mathrm{ml}$ steril saf su içerisine eklenerek spor süspansiyonları hazırlanmıştır. Hazırlanan süspansiyonların dozları Thoma lamı ve ışık mikroskobu yardımıyla $M$. persicae'ye uygulanmak üzere $10^{6}, 10^{7}$ ve $10^{8}$ konidi. $\mathrm{ml}^{-1}$ olarak ayarlanmıştır.

\section{Denemelerin kurulması}

İklim odasında yetiştirilen $M$. persicae bireylerinden rastgele seçilen 10 adet 4 . dönem nimfler tabanında kurutma kağıdı bulunan petri kabındaki biber yaprağı üzerine aktarılmıştır. Ergin döneme gelen yaprakbitleri her gün kontrol edilerek yeni doğan 50 adet yaprakbiti ayrı ayrı olarak petri kaplarındaki temiz biber yapraklarına aktarılmıştır. Her bir petri kabındaki yavrular 2. veya 3 . nimf dönemine geldiğinde Entomopatojen fungus'un hazırlanan süspansiyonuna beş saniye süre ile daldırılmış biber yaprağı bulunan petri kaplarına yine ayrı ayrı olmak üzere aktarılmıştır. Bu uygulama $B$. bassiana'nın LD.2016 ve M6-4 izolatlarının $10^{6}, 10^{7}$ ve $10^{8}$ olmak üzere her üç dozu için gerçekleştirilmiştir. Kontrol uygulaması olarak da \%0.05 Tween 80 içeren steril saf suya daldırılmış yapraklar kullanılmıştır. Böylelikle her bir uygulama için 50 birey kullanılmıştır. Bu şekilde deneme her bir tekerrürde 10 petri olacak şekilde 5 tekerrürlü olarak düzenlenmiştir.

Uygulamadan sonraki 3., 5., 7. ve 9. günlerdeki canlı birey sayıları her bir uygulama için ayrı ayrı olarak kaydedilmiştir. Entomopatojen fungus gelişimini gözlemlemek için ölen yaprakbitleri nemlendirilmiş kurutma kâğıdı içeren petri kaplarındaki lamlar üzerine alınmıştır ve fungus gelişimi binoküler stereo mikroskop altında incelenmiştir (Şekil 1). Deneme $25 \pm 1^{\circ} \mathrm{C}$ ve $\% 60 \pm 10$ nemli ortamda 16 saat aydınlık, 8 saat karanlık koşullara sahip iklim odalarında yürütülmüştür. 


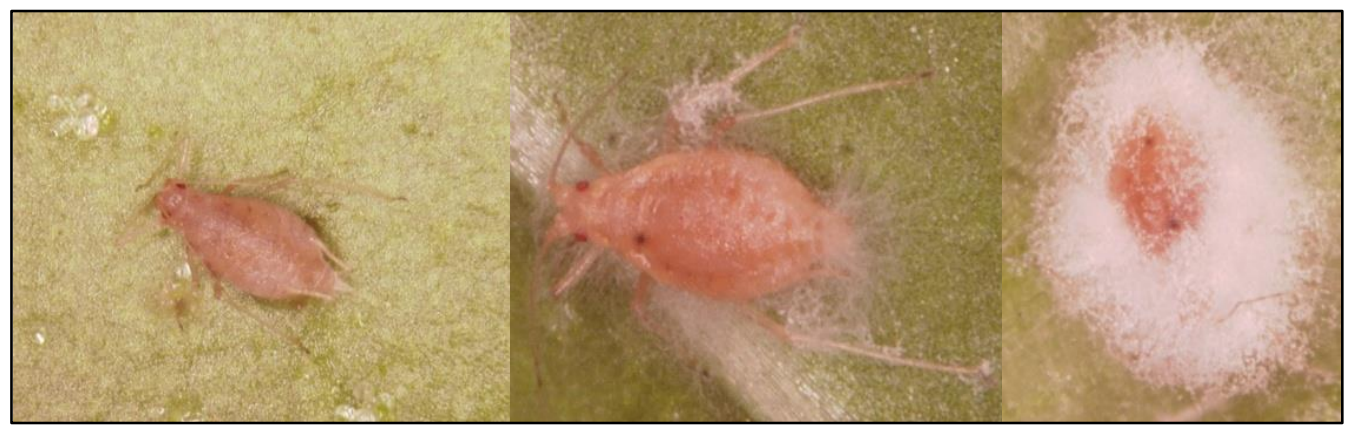

Şekil 1. Beauveria bassiana'nın LD.2016 ve M6-4 izolatlarına maruz kalmış Myzus persicae bireylerindeki fungus gelişiminin aşamaları (Berber, 2020)

\section{Veri Analizi}

Tek faktörlü tesadüf parselleri deneme desenine göre düzenlenen deneme 50 birey üzerinden yürütülmüştür. Her 10 petri bir tekerrür olacak şekilde toplamda 5 tekerrür oluşturulmuştur. Her gün, entomopatojen uygulanmış ve kontrol grubundaki canlı birey sayımları yapılarak hesaplanmış yüzde ölüm değerleri ilk önce homojenite testine tabi tutulmuş, Shapiro-Wilk normallik testi uygulanmıştır. Parametrik olmadığı anlaşılan verilere açı transformasyonu uygulandıktan sonra tek yönlü varyans analizi (One-Way ANOVA) uygulanmıştır. Daha sonra benzer ve farklı grupları belirlemek için de Tukey çoklu karşılaştırma testi (Tukey, 1949) yapılmıştır. İstatistiksel analizler SPSS ${ }^{\circledR} 20.0$ paket programı yardımıyla gerçekleştirilmiştir.

\section{BULGULAR VE TARTIŞMA}

Beauveria bassiana (Bals.) Vuill.'nın LD.2016 ve M6-4 izolatlarının $10^{6}, 10^{7}$ ve $10^{8}$ konidi.ml $^{-1}$ dozlarına maruz kalmış Myzus persicae Sulzer (Hemiptera: Aphididae) bireylerinde görülen yüzde ölüm değerleri Tablo 1'de verilmiştir.

Tablo 1. Beauveria bassiana'nın LD.2016 ve M6-4 izolatlarının farklı dozlarına maruz kalmış Myzus persicae bireylerinde görülen yüzde ölüm değerleri (\%)

\begin{tabular}{|c|c|c|c|c|c|c|}
\hline & Doz & 1. Gün & 3. Gün & 5. Gün & 7. Gün & 9. Gün \\
\hline \multirow{4}{*}{ 'ొ } & Kontrol & $0.00 \pm 0.00 a$ & $0.00 \pm 0.00 a$ & $2.00 \pm 2.00 a$ & $2.00 \pm 2.00 \mathrm{~b}$ & $2.00 \pm 2.00 c$ \\
\hline & $10^{6}$ & $0.00 \pm 0.00 a$ & $2.00 \pm 2.00 a$ & $4.00 \pm 2.45 a$ & $8.00 \pm 3.74 b$ & $20.00 \pm 7.75 c$ \\
\hline & $10^{7}$ & $0.00 \pm 0.00 \mathrm{a}$ & $2.00 \pm 2.00 \mathrm{a}$ & $4.00 \pm 2.45 a$ & $22.00 \pm 12.41 \mathrm{~b}$ & $58.00 \pm 14.63 b$ \\
\hline & $10^{8}$ & $0.00 \pm 0.00 \mathrm{a}$ & $0.00 \pm 0.00 \mathrm{a}$ & $12.00 \pm 7.35 a$ & $62.00 \pm 12.81 \mathrm{a}$ & $98.00 \pm 2.00 \mathrm{a}$ \\
\hline \multirow{4}{*}{$\stackrel{\text { J }}{\stackrel{0}{\Sigma}}$} & Kontrol & $0.00 \pm 0.00 \mathrm{~b}$ & $0.00 \pm 0.00 \mathrm{~b}$ & $2.00 \pm 2.00 \mathrm{~b}$ & $2.00 \pm 2.00 \mathrm{c}$ & $2.00 \pm 2.00 \mathrm{~b}$ \\
\hline & $10^{6}$ & $0.00 \pm 0.00 \mathrm{~b}$ & $0.00 \pm 0.00 \mathrm{~b}$ & $0.00 \pm 0.00 \mathrm{~b}$ & $10.00 \pm 6.32 c$ & $18.00 \pm 8.00 b$ \\
\hline & $10^{7}$ & $0.00 \pm 0.00 \mathrm{~b}$ & $0.00 \pm 0.00 \mathrm{~b}$ & $12.00 \pm 3.74 b$ & $38.00 \pm 7.35 b$ & $70.00 \pm 13.78 a$ \\
\hline & $10^{8}$ & $8.00 \pm 3.74 a$ & $18.00 \pm 6.63 a$ & $30.00 \pm 6.32 a$ & $80.00 \pm 3.16 a$ & $92.00 \pm 5.83 a$ \\
\hline
\end{tabular}

${ }^{*}$ Her bir izolat için ayrı ayrı olmak üzere aynı sütunda farklı harfleri taşıyan ortalamalar ( \pm standart hatalar) arasındaki farklar istatistiksel olarak önemlidir (Tukey's HSD test, $p>0.05 ; n=5$, her bir uygulama 50 birey üzerinden yürütülmüştür).

LD.2016 izolatı uygulandıktan sonraki 1., 3. ve 5. günlerde $M$. persicae bireylerinde görülen ölüm oranları ile kontrol grubundaki bireylerde görülen ölüm oranları arasındaki farklar istatistiksel olarak önemsiz bulunmuştur. LD.2016 izolatının $10^{8}$ konidi.ml $^{-1}$ dozuna maruz kalmış bireylerin 7 . gündeki yüzde ölüm değerleri $\% 62$ olarak hesaplanmış olup diğer dozlardan ve kontrol grubundan farklı bir istatistiksel grupta yer almıştır. Uygulamadan sonraki 9. günde $10^{7}$ konidi.ml $^{-1}$ dozuna maruz kalan bireylerde yüzde ölüm değerleri $\% 58,10^{8}$ konidi.ml $^{-1}$ dozuna maruz kalmış bireylerde ise $\% 98$ olarak hesaplanmış olup kontrol grubundaki bireylerde görülen ölüm oranları ile aralarındaki fark istatistiksel olarak önemli bulunmuştur (Çizelge 1).

M6-4 izolatı uygulandıktan sonraki 1., 3. ve 5. günlerde $10^{6}$ ve $10^{7}$ konidi.ml ${ }^{-1}$ dozuna maruz kalan $M$. persicae bireylerinde görülen ölüm oranları kontrol grubu ile aynı istatistiksel grupta yer almıştır. Uygulama yapıldıktan

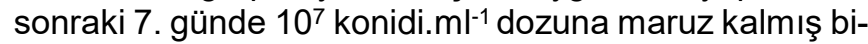
reylerdeki yüzde ölüm değerleri $\% 38,10^{8}$ dozuna maruz kalmış bireylerde ise $\% 80$ olarak bulunmuştur ve kontrol grubundaki bireylerde görülen yüzde ölüm değerlerine göre istatistiksel olarak farklı bir grupta yer almışlardır. Uygulamadan sonraki 9. günde ise $10^{7}$ ve $10^{8}$ konidi. 
$\mathrm{ml}^{-1}$ dozlarına maruz kalmış bireylerde görülen yüzde ölüm değerleri sırasıyla $\% 70$ ve $\% 92$ olarak bulunmuş olup, $10^{6}$ dozuna maruz kalmış bireylerde ve kontrol grubundaki bireylerde görülen yüzde ölüm değerlerinden istatistiksel olarak önemli derecede farklı bulunmuştur (Tablo 1).

Beauveria bassiana'nın LD.2016 ve M6-4 izolatlarının $10^{6}, 10^{7}$ ve $10^{8}$ konidi.ml-1 dozlarının M. persicae üzerindeki etkileri ile ilgili yapılan çalışmanın sonucunda, uygulamadan sonraki 7 . günden itibaren etkili olmaya başlayan LD.2016 ve M6-4 izolatlarının $10^{8}$ konidi.ml- $^{-1}$ dozuna maruz kalmış bireylerindeki yüzde ölüm değerleri sırasıyla \%62 ve \%80 olarak bulunmuştur. Her iki izolat için de en fazla yüzde ölüm değerleri 9 . günde $10^{8}$ konidi.ml ${ }^{-1}$ doz uygulamasında sırasıyla $\% 98$ ve $\% 92$ olarak hesaplanmıştır. Çalışma boyunca uygulanan izolatların dozlarının artmasına bağlı olarak yüzde ölüm değerlerinde de artış olduğu görülmüştür. Saranya ve ark. (2010) yaptıkları çalışmada, Aphis craccivora Koch (Hemiptera: Aphididae)'ya karşı farklı entomopatojen fungusların 6 farklı konsantrasyonlarını $\left(10^{3}, 10^{4}, 10^{5}, 10^{6}\right.$, $10^{7}$ ve $10^{8}$ konidi.ml $^{-1}$ ) denemişlerdir ve bunlardan $B$. bassiana'nın $10^{8}$ konidi. $\mathrm{ml}^{-1}$ konsantrasyonu uygulanmış bireylerindeki yüzde ölüm değerlerini 7 . günün sonunda \%96.66 olarak belirlemişlerdir. Akmal ve ark. (2013) entomopatojen fungus $B$. bassiana'nın $10^{6}, 10^{7}$ ve $10^{8}$ konidi.ml-1 dozlarını Brevicoryne brassicae (L.) (Hemiptera:
Aphididae)'ye karşı uygulamışlardır ve uygulamadan sonraki 7. günde bireylerdeki maksimum yüzde ölüm değerini (\%100) $10^{8}$ konidi.ml $^{-1}$ dozuna maruz kalmış bireylerde gözlemlemişlerdir. Jandricic ve ark. (2014) yaptıkları çalışmada sera zararlıları olan M. persicae, Aphis gossypii Glover ve Aulacorthum solani (Kalt.) (Hemiptera: Aphididae)'ye karşı B. bassiana ve Metarhizium anisopliae (Metsch.) Sorok.'nın patojenliklerini değerlendirmişlerdir ve sonuç olarak $B$. bassiana izolatları uygulanmış $M$. persicae bireylerindeki yüzde ölüm değerlerinin \%62'ye kadar yükseldiğini belirtmişlerdir. Javed ve ark. (2019) entomopatojen fungus B. bassiana ve Lecanicillium lecanii (Zimm.) Zare \& Gams'nin farklı izolatla-

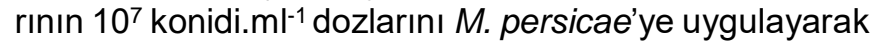
patojenliklerini değerlendirmişlerdir ve uygulamadan sonraki 10. günde yüzde ölüm değerlerinin her iki fungus için de \%80'den daha fazla olduğunu belirtmişlerdir. Bahsedilen çalışmalarda bulunan sonuçlarla, bu çalışmada elde edilen bulgular paralellik göstermektedir. Beauveria bassiana'nın LD.2016 ve M6-4 izolatlarının $10^{8}$ konidi.ml ${ }^{-1}$ dozuna maruz kalmış $M$. persicae bireylerinin yüzde ölüm oranları üzerine çizilmiş regresyon eğrisi $(P<0.01)$ ve LT50 değerleri Şekil 2'de verilmiştir. Bu grafiğe göre LD.2016 izolatının $10^{8}$ konidi.ml $^{-1}$ dozuna maruz kalmış $M$. persicae bireylerinin $\mathrm{LT}_{50}$ değeri 6.19 gün olarak bulunmuştur. M6-4 izolatının $10^{8}$ konidi.ml-1 dozuna maruz kalmış bireylerde ise bu değer 5.5 gün olarak hesaplanmıştır (Şekil 2).

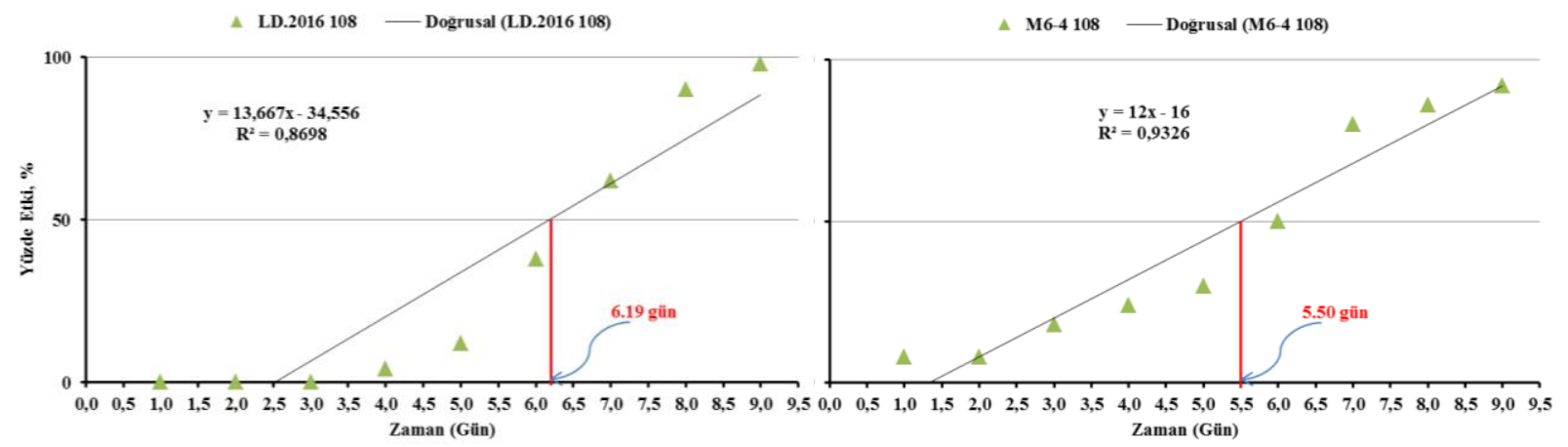

Şekil 2. Beauveria bassiana'nın LD.2016 ve M6-4 izolatlarının $10^{8}$ dozuna maruz kalmış Myzus persicae bireylerinin yüzde ölüm oranları üzerine çizilmiş regresyon eğrisi $(P<0.01)$ ve $L T 50$ değeri 
Yapılan çalışma sonucunda LD.2016 ve M6-4 izolatlarının dozları arttıkça $L T_{50}$ değerlerinde azalma olduğu görülmüştür. Vu ve ark. (2007) yaptıkları çalışmada, 12 farklı fungus türünün $10^{5}, 10^{6}, 10^{7}$ ve $10^{8}$ konidi.ml- $^{-1}$ dozlarını $M$. persicae ve $A$. gossypii üzerine uygulamışlar ve doz ile $\mathrm{LT}_{50}$ değeri arasında ters bir orantı olduğunu belirlemişlerdir. Saranya ve ark. (2010) A. craccivora'ya karşı farklı entomopatojen fungusların etkinliklerini denemişler ve $\mathrm{LT}_{50}$ değerlerinin konsantrasyon arttıkça azaldığını belirtmişlerdir. Tuncer ve ark. (2018) yaptıkları çalışmada $B$. bassiana TR-217 entomopatojen fungus izolatını ve $B$. bassiana (Bio-Power) ticari preparatını fındık kurdu erginlerine karşı uygulamışlar ve $B$. bassiana TR-217 izolatının $L_{50}$ değerini 4.64 gün, $B$. bassiana'nın ticari preparatının ise 6.16 gün olarak hesaplamışlardır. Bu sonuçlara göre; LT 50 değerlerine bakılarak $B$. bassiana'nın izolatının preparatına göre daha kısa süre içinde etki gösterdiğini belirtmişlerdir.

Yapılan çalışma sonucunda $M$. persicae'e uygulanan LD.2016 ve M6-4 izolatlarının patojenlikleri arasında önemli bir fark olmadığı belirlenmiştir. McGuire ve ark. (2006) yaptıkları denemelerde bir tanesi ticari ürün olmak üzere 3 farklı B. bassiana izolatını Lygus hesperus Knight (Hemiptera: Miridae) zararlısı üzerinde denemişler ve izolatlar arasında bir fark olmadığını belirtmişlerdir. Meyers ve ark. (2013) yaptıkları çalışmada iki farklı B. bassiana izolatını Enaphalodes rufulus (Haldeman) (Coleoptera: Cerambycidae) üzerinde uygulamışlar ve kullanılan iki izolatın larvalar üzerindeki etkileri arasında önemli bir fark görmemişlerdir. Bahsedilen çalışmalar ile bu çalışma benzer şekilde bulunmuştur.

Sonuç olarak, her iki izolatın da spor konsantrasyonları arttıkça yüzde ölüm oranları da artmıştır fakat $L_{50}$ değerlerinde ise azalma olduğu belirlenmiştir. Bu entomopatojen fungus izolatlarının M. persicae'ye karşı uygulanacak entegre mücadele yöntemi kapsamında kullanımlarının ümit var olduğu görülmektedir. Entomopatojen fungusların, memeliler üzerinde herhangi bir toksik etkilerinin bulunmaması (Sevim ve ark., 2015) sebebiyle kimyasallar yerine kullanılabilecek uygun bir alternatif olabilmesi söz konusu olacaktır. Daha sonra yapılacak çalışmalarda bu fungusun izolatlarının tarla ve sera şartlarındaki etkinliklerinin test edilmesinde yarar vardır. Ayrıca bu entomopatojenlerin yaban hayatı ve doğal düşmanlara etkilerinin belirlenmesi gerekmektedir. İleri çaış̧malarda başarılı olunması durumunda, bu izolatların M. persicae'ye karşı hazırlanacak bir entegre zararlı yönetimi programı kapsamındaki biyolojik mücadele uygulamalarında yer alabileceği düşünülmektedir.

\section{TEŞEKKÜR}

Bu çalışma, "Entomopatojen fungus, Beauverıa bassiana (Balsamo) vuillemin (Ascomycota: Hypocreales)'nın iki farklı izolatının Myzus persicae Sulzer (Hemiptera: Aphididae) üzerine etkileri” başlıklı yüksek lisans tez verileri kullanılarak hazırlanmıştır.

\section{KAYNAKLAR}

Akmal, M., Freed, S., Malik, M. N., Gul, H. T. (2013). Efficacy of Beauveria bassiana (Deuteromycotina: Hypomycetes) against different aphid species under laboratory conditions. Pakistan Journal of Zoology, 45(1): 71-78.

Azizoğlu, U., Bulut, S., Yılmaz, S. (2012). Organik tarımda biyolojik mücadele; entomopatojen biyoinsektisitler. Erciyes Üniversitesi Fen Bilimleri Enstitüsü Dergisi, 28(5): 375-381.

Baydar, R., Güven, Ö., Karaca, İ. (2016). Occurrence of entomopathogenic fungi in agricultural soils from Isparta Province in Turkey and their pathogenicity to Galleria mellonella (L.) (Lepidoptera: Pyralidae) Larvae. Egyptian Journal of Biological Pest Control, 26(2): 323-327.

Çelebi, Ö. (2012). Eurygaster integriceps (Put.) (Hemiptera: Scutelleridae)'in Bakteriyal Florasinin ve Mikrobiyal Mücadele Etmenlerinin Belirlenmesi. (Yüksek Lisans Tezi, Recep Tayyip Erdoğan Üniversitesi, Fen Bilimleri Enstitüsü)

Demirci, F., Muştu, M., Kaydan, M. B., Ülgentürk, S. (2011). Laboratory evaluation of the effectiveness of the entomopathogen; Isaria farinosa, on Citrus mealybug, Planococcus citri. Journal of Pest Science, 84: 337-342.

Erdoğan, P. (2015). Capsicum annuum L. (Solanaceae) ve Allium sativum L. (Amaryllidaceae) ekstraktlarının Myzus persicae (Sulzer) (Hemiptera: Aphididae) üzerine insektisit etkisi. Bitki Koruma Bülteni, 55(4): 305-315.

Güven, Ö., Baydar, R., Temel, C., Karaca, İ. (2014). Bazı entomopatojen fungusların Aphis Fabae (Scopoli) (Hemiptera: Aphididea) üzerine etkileri. Türkiye Biyolojik Mücadele Dergisi, 5(2): 149-158.

İnanlı, C., Yoldaş, Z., Birgücü, A. K. (2012). Entomopatojen funguslar Beauveria bassiana (Bals.) ve Metarhizium anisopliae (Metsch.)'nin Tuta absoluta (Meyrick) (Lepidoptera:Gelechiidae)'nın yumurta ve larva dönemlerine etkisi. Ege Üniversitesi Ziraat Fakültesi Dergisi, 49(3): 239-242.

Jandricic, S. E., Filotas, M., Sanderson, J. P., Wraight, S. P. (2014). Pathogenicity of conidia-based preparations of entomopathogenic fungi against the greenhouse pest aphids Myzus persicae, Aphis gossypii, and Aulacorthum solani (Hemiptera: Aphididae). Journal of Invertebrate Pathology, 118: $34-46$.

Javed, K., Javed, H., Mukhtar, T., Qiu, D. (2019). Pathogenicity of some entomopathogenic fungal strains to green peach aphid, Myzus persicae Sulzer (Homoptera: Aphididae). Egyptian Journal of Biological Pest Control, 29(92). https://doi.org/10.1186/s41938-019-0183-z

Kontodimas, D. C., Eliopoulos, P. A., Stathas, G. J., Economou, L. P. (2004). Comparative temperature-dependent development of Nephus includens (kirsch) and Nephus bisignatus (boheman) (coleoptera: coccinellidae), preying on Planococcus citri (risso) (homoptera: pseudococcidae): Evaluation of a linear and various non-linear models using specific criteria. Environmental Entomology, 33: 1-11. 
McGuire, M. R., Leland, J. E., Dara, S., Park, Y. H., Ulloa, M. (2006). Effect of different isolates of Beauveria bassiana on field populations of Lygus hesperus. Biological Control, 38(3): 390-396.

Meyers, J. M., Stephan F. M., Haavik, L. J., Steinkraus, D. C (2013). Laboratory and field bioassays on the effects of Beauveria bassiana Vuillemin (Hypocreales: Cordycipitaceae) on red oak borer, Enaphalodes rufulus (Haldeman)(Coleoptera: Cerambycidae). Biological Control, 65(2): 258-264.

Özçelik, N., Bal, G., Demirci, F., Muştu, M. (2013). Isaria farinosa ve Purpureocillium lilacinum'un yeşil şeftali yaprakbiti, Myzus persicae (Sulzer) (Hemiptera: Aphididae) üzerine etkileri. Türkiye Biyolojik Mücadele Dergisi, 4(1): 23-29.

Rath, A. C. (2000). The use of entomopathogenic fungi for control of termites. Biocontrol Science and Technology, 10: 563-581.

Saranya, S., Ushakumari, R., Jacob, S., Philip, M. B. (2010). Efficacy of different entomopathogenic fungi against cowpea aphid, Aphis craccivora (Koch). Journal of Biopesticides, 3(1):138-142.

Sevim, A., Sevim, E., Demirbağ, Z. (2015). Entomopatojenik fungusların genel biyolojileri ve Türkiye'de zararlı böceklerin mücadelesinde kullanılma potansiyelleri. Fen Bilimleri Enstitüsü Dergisi, 8(1): 115-147.
Tukey, J. W. (1949). Comparing individual means in the analyses of variance. Biometrics, 5: 99-114.

Tuncer, C., Kushiyev, R., Liu, J., Akça, İ. (2018). Metarhizium anisopliae ve Beauveria bassiana izolat ve preparatlarının Curculio nucum'a karşı etkinlikleri. Anadolu Tarım Bilimleri Dergisi, 1308-8750. Doi: 10.7161/omunajas.387380.

Uzuner, S., Güner, B. G., Ayar, Ö., Yaman, M. (2017). Biyolojik mücadelede kullanılan entomopatojenlerin arılar üzerine etkileri. Arıcılık araştırma dergisi, 9(1): 9-19.

Velioğlu, A. S., Toros, S. (2002). Değişik bölgelerden toplanan Myzus persicae (Sulz.) (Hom.: Aphididae) popülasyonlarının bazı insektisitlere karşı dayanıklılık düzeylerinin araştırılması. Bitki Koruma Bülteni, 42(1-4): 67-79.

Vu, H. V., Hong.,S., Kim, K. (2007). Selection of entomopathogenic fungi for aphid control. Journal of Bioscience and Bioengineering, 104(6): 498-505.

Zimmermann, G. (1986). The 'Galleria bait method' for detection of entomopathogenic fungi in soil. Journal of Application Entomology, 102: 213-215.

Zimmermann, G. (2007). Review on safety of the entomopathogenic fungi Beauveria bassiana and Beauveria brongniartii. Biocontrol Science and Technology, 17: 553-596. 